BNL-113163-2016-JA

\title{
Surface modified pinecone shaped hierarchical structure fluorinated mesocarbon microbeads for ultrafast discharge and improved electrochemical performances
}

Yang Dai, Yuan Fang, Sendan Cai, Lijun Wu, Weijing Yang, Hao Yan, Jingying Xie, Jin-Cheng Zheng, Esther Takeuchi, and Yimei Zhu

Submitted to Journal of The Electrochemical Society

November 2016

\author{
Condensed Matter Physics and Material Science Department \\ Brookhaven National Laboratory
}

\author{
U.S. Department of Energy \\ USDOE Office of Science (SC), \\ Basic Energy Sciences (BES) (SC-22)
}

Notice: This manuscript has been authored by employees of Brookhaven Science Associates, LLC under Contract No. DE-SC0012704 with the U.S. Department of Energy. The publisher by accepting the manuscript for publication acknowledges that the United States Government retains a non-exclusive, paid-up, irrevocable, world-wide license to publish or reproduce the published form of this manuscript, or allow others to do so, for United States Government purposes. 


\section{DISCLAIMER}

This report was prepared as an account of work sponsored by an agency of the United States Government. Neither the United States Government nor any agency thereof, nor any of their employees, nor any of their contractors, subcontractors, or their employees, makes any warranty, express or implied, or assumes any legal liability or responsibility for the accuracy, completeness, or any third party's use or the results of such use of any information, apparatus, product, or process disclosed, or represents that its use would not infringe privately owned rights. Reference herein to any specific commercial product, process, or service by trade name, trademark, manufacturer, or otherwise, does not necessarily constitute or imply its endorsement, recommendation, or favoring by the United States Government or any agency thereof or its contractors or subcontractors. The views and opinions of authors expressed herein do not necessarily state or reflect those of the United States Government or any agency thereof. 


\section{Surface modified pinecone shaped hierarchical structure fluorinated mesocarbon}

microbeads for ultrafast discharge and improved electrochemical performances Yang Dai ${ }^{\mathrm{a}}$, Yuan Fang ${ }^{\mathrm{a}}$, Sendan $\mathrm{Cai}^{\mathrm{a}}$, Lijun $\mathrm{Wu}^{\mathrm{c}}$, Weijing Yang ${ }^{\mathrm{a}}$, Hao Yan ${ }^{\mathrm{a}}$, Jingying $\mathrm{Xie}^{\mathrm{a}, \mathrm{d}, \mathrm{z}}$,Jin-Cheng Zheng ${ }^{\mathrm{b}, \mathrm{z}}$, Esther Takeuchi ${ }^{\mathrm{e}}$, and Yimei Zhu ${ }^{\mathrm{c}, \mathrm{z}}$

${ }^{\mathrm{a}}$ Department of Chemical Engineering, School of Environmental and Chemical

Engineering, Shanghai University, Shangda Road 99, Shanghai, 200444, China

${ }^{\mathrm{b}}$ Department of Physics, and Fujian Provincial Key Laboratory of Theoretical and

Computational Chemistry, Xiamen University, Xiamen 361005, China; and Xiamen University Malaysia, 439000 Sepang, Selangor, Malaysia

${ }^{\mathrm{c}}$ Condensed Matter Physics \& Materials Science Department, Brookhaven National Laboratory, Upton, New York 11973, United States

${ }^{\mathrm{d}}$ Department of Mechanical Engineering, University of California at Berkeley, Berkeley, California 94720, United States

${ }^{\mathrm{e}}$ Department of Materials Science and Engineering, Stony Brook University, Stony Brook, NY 11794-2275, USA

Among all primary lithium batteries, $\mathrm{Li} / \mathrm{CF}_{\mathrm{x}}$ primary battery possesses the

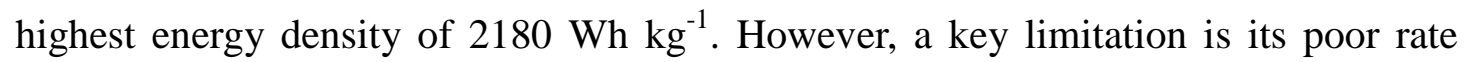
capability because the cathode material $\mathrm{CF}_{\mathrm{x}}$ is intrinsically a poor electronic conductor. Here, we developed a so-called “doing subtraction” method to modify the 
pinecone shaped fluorinated mesocarbon microbead (F-MCMB). The modified fluorinated mesocarbon microbead (MF-MCMB), manifests the advantage of open-framed structure, possesses good electronic conductivity and removes transport barrier for lithium ions. Thus, high capacity performance and excellent rate capability without compromising capacity can be obtained. A capacity of $343 \mathrm{mAhg}^{-1}$ and a maximum power density of $54600 \mathrm{~W} \mathrm{~kg}^{-1}$ are realized at an ultrafast rate of $40 \mathrm{C}$ (28A $\left.\mathrm{g}^{-1}\right)$. In addition, the MF-MCMB cathode does not show any voltage delay even at 5C during the discharge, which is a remarkable improvement over the state-of-the-art $\mathrm{CF}_{\mathrm{X}}$ materials.

Keywords: hierarchical structure, fluorinated mesocarbon microbeads, ultrafast discharge, voltage delay

${ }^{\mathrm{z}}$ Corresponding authors: Tel: 86(021) 62131647(Jingying Xie), 86(592)2182630 (Jin-Cheng Zheng) (631)344-3057, (Yimei Zhu) E-mail: jyxie@mail.sim.ac.cn (Jingying Xie), jczheng@xmu.edu.cn (Jin-Cheng Zheng) and zhu@bnl.gov (Yimei Zhu) 
The Li/CF $\mathrm{Cr}_{\mathrm{x}}$ primary battery is the first lithium battery developed in the1970's ${ }^{1-3}$, and possesses the highest energy-density among all primary lithium batteries (theoretically $2180 \mathrm{Whkg}^{-1}$, where some recent reports even exceed the theoretical capacity ${ }^{4,5}$ ). The $\mathrm{CF}_{\mathrm{x}}$ chemical system offers long service-life, high reliability, a wide range of operating temperatures and excellent electrochemical performance that are suitable for applications in critical environments, such as deep underground, in tire-pressure monitoring systems, implantable medical devices ${ }^{6-8}$ and the emerging wearable devices. However, the $\mathrm{Li} / \mathrm{CF}_{\mathrm{x}}$ battery is known to suffer from kinetic problems due to the intrinsically poor electronic conductivity of the cathode material $\mathrm{CF}_{\mathrm{x}}$, inhibiting its application in high-power devices ${ }^{2-13}$. Considerable efforts have been devoted to addressing these problems. Various structures and nanoscale carbon materials, such as carbon disc ${ }^{5}$, carbon nano-fibre ${ }^{9}$, carbon nanotube, fullerene ${ }^{12}$, and ordered meso-porous carbon ${ }^{14}$, and graphene ${ }^{15}$ were fluorinated by various methods to improve their electrochemical performances. The fluorinated carbon fibre can provide an impressive $8057 \mathrm{Wkg}^{-1}$ power density (6 C) with a capacity of $440 \mathrm{mAhg}^{-1} 13$. Other approaches have been used to improve the $\mathrm{CF}_{\mathrm{x}}$ behaviour through material modification. Generally, researchers usually applied the "adding other materials" methods to achieve the modification, such as polypyrrole coating ${ }^{11}$, carbon-thermal treatment $^{16}$, and graphene/SVO ball milling ${ }^{10}$. In addition, electrolyte ${ }^{17}$ and current collector replacement are two effective strategies ${ }^{18,19}$.

These methods can solve the problem to some extent. However, the rate capability remains limited to a discharge rate less than $10 \mathrm{C}$ where the $\mathrm{CF}_{\mathrm{x}}$ cathodes exhibit low capacity at high rates (termed "low Faradic yield") ${ }^{20,21}$. Another interesting but unpleasant phenomenon existing in the $\mathrm{CF}_{\mathrm{x}}$ battery is the voltage delay, which will 
block its further application in some areas. While importantly, the voltage delay has been largely neglected and deemed inherent to the electrochemical performance in most cases without further discussion except some reports which attribute the phenomenon to the poor electron conductivity of the $\mathrm{CF}_{\mathrm{x}}{ }^{2-20}$. Thus, retarding the voltage delay and improving the rate performance of the $\mathrm{CF}_{\mathrm{x}}$ battery remains a big challenge. Most recently, we report an alternative approach, called "doing subtraction" to modify highly fluorinated Daikin $\mathrm{CF}_{\mathrm{x}}$, achieving an ultrahigh power density of $48400 \mathrm{~W} \mathrm{~kg}^{-1}$ at $30 \mathrm{C}$, associated with a capacity of $500 \mathrm{mAh} \mathrm{g}$. As a general approach, the method provides the particles of $\mathrm{CF}_{\mathrm{x}}$ with a metallic-like conductive surface, which not only lowers the resistance, but also removes the inert groups (such as $-\mathrm{CF}_{2}$ and $-\mathrm{CF}_{3}$ ), increasing the paths for ion transport. Interestingly, the discharge plateau rises to $2.65 \mathrm{~V}$ without any voltage delay at a low rate of $0.025 \mathrm{C}$, however, the voltage delay is rate dependent and becomes obvious when the discharge rate increases ${ }^{18}$. Thus, the issue arises on how to improve the rate performances and simultaneously retard the voltage delay.

An interesting structure existing in the nature is the pinecone, with an open framework structure. We hypothesize that if the $\mathrm{CF}_{\mathrm{x}}$ material possesses micro-size grains with a pine-cone shaped hierarchical structure, it will be beneficial for ion transport and electrode fabrication. Inspired by the hierarchical structure of the pinecone, here, we report using our developed “doing subtraction” approach under mild hydrothermal conditions $^{21}$ to modify the pinecone shaped fluorinated mesocarbon microbead (F-MCMB) $\mathrm{CF}_{\mathrm{x}}(\mathrm{x}=0.86)$. With an electrical conductive surface, more open frame structure, and with barrier free ion transport, the innate rate capability of the modified F-MCMB is revealed to be rather high. We demonstrated 
that, the modified fluorinated mesocarbon microbead (MF-MCMB) can achieve an ultrahigh power density of $54600 \mathrm{Wkg}^{-1}$ at $40 \mathrm{C}$, with a capacity of $343 \mathrm{mAhg}^{-1}$. The result is better than that of the modified $\mathrm{CF}_{\mathrm{X}}$ we recently reported. Furthermore, the voltage delay can also be minimized even at a rate of $5 \mathrm{C}$. The electrochemical performance, especially the rate capability and the inhibition of voltage delay are significantly improved compared to the reports in the existing literatures.

\section{Experimental}

\section{Modification of $\mathrm{CF}_{x}$}

Modified $\mathrm{CF}_{\mathrm{x}}$ was synthesized by a simple hydrothermal reaction between precursor F-MCMB (Zhuoxi Corp, Hubei, China, $\mathrm{x}=0.86$ ) and base water/ethanol mixed solution. In a typical procedure, $\mathrm{NaOH}(0.72 \mathrm{~g})$ and $\mathrm{CH}_{3} \mathrm{CH}_{2} \mathrm{OH}$ /water mixture (90mL, 50/50 v/v \%) was blended by ultra-sonication for 1 min. Then, the mixture was transferred into a $150 \mathrm{~mL}$ Teflon-lined autoclave and maintained at $180^{\circ} \mathrm{C}$ for $8 \mathrm{~h}$. Afterwards, the autoclave was naturally cooled to room temperature, and the product was subsequently filtered through a microporous membrane and washed throughout with ultrapure water. Finally, the modified $\mathrm{CF}_{\mathrm{x}}$ was obtained by vacuum drying at $60^{\circ} \mathrm{C}$ for 24 hours. The $\mathrm{C} / \mathrm{F}$ ratios of the $\mathrm{CF}_{\mathrm{x}}$ were determined by a chemical method and carried out in Shanghai Institute of Organic Chemistry, Chinese Academy of Science (CAS).

\section{Material Characterization}

The surface morphologies of the $\mathrm{CF}_{\mathrm{x}}$ were examined using Hitachi S3400N scanning electron microscopy (SEM). High resolution transmission electron microscopy (HRTEM) and scanning transmission electron microscopy (STEM) 
modes and electron energy loss spectroscopy (EELS) were performed using the double aberration-corrected JEM-ARM200CF microscope operated at $200 \mathrm{kV}$. The microscope is equipped with JEOL and Gatan high angle annular dark field (HAADF) detectors for incoherent HAADF (Z-contrast) imaging, Gatan GIF Quantum ER Energy Filter with dual EELS for EELS. The relative compositions of $\mathrm{C}$ and $\mathrm{F}$ was derived from the $\mathrm{K}$ edges of $\mathrm{C}$ and $\mathrm{F}$, respectively, using the Gatan Digital Micrograph software. The structure of the samples was characterized by X-ray diffraction (XRD) using D8 advance (Broker). X-ray photoelectron spectroscopy (XPS) was performed using AXIS UTLTRADLD (SHIMADZU) followed by the Casa XPS software to analysis the results. A Shirley-type background was removed from the spectra before de-convolution. The FTIR was characterized by Nicolet iN10 (Thermo Scientific). The Raman spectra were performed using a Renishaw Reflex with laser excitation $(\lambda=532.5 \mathrm{~nm})$. The porous texture of the $\mathrm{CF}_{\mathrm{x}}$ was analyzed by $\mathrm{N}_{2}$ adsorption at $77 \mathrm{~K}$, respectively (ASAP 2020). Before the measurements, the samples were outgassed at $150{ }^{\circ} \mathrm{C}$ overnight under vacuum. The specific surface area was calculated from the nitrogen adsorption isotherms by applying the BET and Dubinin-Radushkevich equations. To measure the electrical conductivity of the F-MCMB and MF-MCMB, $95 \mathrm{wt} \% \mathrm{CF}_{\mathrm{x}}$ powder and $5 \mathrm{wt} \%$ PTFE were mixed and pressed at $20 \mathrm{MPa}$ to form a disc with a diameter of $18 \mathrm{~mm}$ and a thickness of $500 \mu \mathrm{m}$, respectively. And the electrical conductivity was determined with a four point probe meter (SB118 QianFeng, Shanghai).

Electrode Fabrication and electrochemical measurements

F-MCMB or MF-MCMB (80 wt\%) powder, PVDF resin (10 wt\%, Kynar 761), and vapor grown carbon fiber (VGCF, 10\%, Showa Denko Co.) were mixed and stirred vigorously in the presence of N-methyl-2-pyrrolidone to form a uniform slurry. 
The cathodes were prepared by spreading the same slurry onto carbon coated aluminum foil $(18 \mu \mathrm{m})$ current collectors. The thickness of the composite active layers is set around $25 \mu \mathrm{m}$ after drying and rolling depression. Then the coated Al foil was punched into disks of $14 \mathrm{~mm}$ in diameter, of which, the mass loading were about 1-1.5 mg. The theoretically capacity of the $\mathrm{CF}_{\mathrm{x}}$ was calculated using $\mathrm{Q}=x F /[3.6(12+19 x)]$ (where $x$ is the fluorine content, $F$ is the Faraday constant $96,485 \mathrm{Cmol}^{-1}$ and 3.6 is the conversion constant $\left.{ }^{16}\right) \cdot 1 \mathrm{M} \mathrm{LiBF}_{4}$ in PC/DME (v/v=1:1) (BASF) was used as the electrolyte.

A potentiostat system (Princeton applied research1287+1260/1255B) was used for AC impedance measurements. The measurement was carried out using a coin cell, with a lithium foil as the counter and reference electrode. AC impedance measurements were performed over the frequency range of $0.1 \mathrm{~Hz}-100 \mathrm{kHz}$ with an amplitude of $5 \mathrm{mV}$ at room temperature. The discharge performances were tested on a battery measurement system (Land CT 2001A Wuhan) at room temperature.

\section{Results and Discussion}

\section{Results}

The color of the pristine F-MCMB is dark green, indicating the precursor is not highly fluorinated (because the MCMB is hard to highly be fluorinated). After the hydrothermal process, the C-F bond on the surface of the pristine F-MCMB is activated to form a new shell, leaving $\mathrm{F}^{-}$in the solution. Thus, the color of modified $\mathrm{CF}_{\mathrm{x}}$ turns dark black, with the $\mathrm{F}$ content decreasing from 57.7 to $55.8 \mathrm{wt} \%$. The wettability of the material turns from hydrophobic to hydrophilic. After modification, the electrical conductivity is enhanced from $3.2 \times 10^{-8} \mathrm{~S} \mathrm{~cm}^{-1}$ to $4.8 \times 10^{-6} \mathrm{~S} \mathrm{~cm}^{-1}$, by two order of magnitude. And the BET surface increases from $120.9 \mathrm{~m}^{2} \mathrm{~g}^{-1}$ for 
F-MCMB to $154.5 \mathrm{~m}^{2} \mathrm{~g}^{-1}$ for MF-MCMB. Since the reaction is mainly on the particle surface, the improved electrical conductivity and BET area can be attributed to the surface modification. This reduction of surface $\mathrm{F}$ content can also affect the contrast quality of the SEM images. Figure 1 (a) shows the pinecone shaped hierarchical structure and the morphology of pristine F-MCMB with particles size of about several hundred nanometers gathered into a conglomeration of ten to twenty micrometers. The conglomeration is a highly open structure with various cracks and pores. The porous structure formation is due to the surface tension release during the fluorinated process. And this structure will facilitate the electrolyte permeation ${ }^{25}$. The edges of the ball-shaped particles are still a little blur, indicating their poor conductivity. In comparison, the SEM image of the modified one is much clearer (Fig. 1 (b)), suggesting the superior electron conductivity after the treatment. In addition, the morphology of the particles of MF-MCMB turns out to be more porous. This might be induced by being "activated" by alkali ions under the high temperature and pressure hydrothermal conditions.

The F-MCMB peaks in the XRD pattern (Fig. 2) correspond to the fluorinated phases, with $2 \theta \approx 13.7^{\circ}, 26.4^{\circ}, 41.1^{\circ}$, and $73.8^{\circ}$ assigned, respectively, to the C-F (002) ( referred as $\mathrm{P}_{1}$ below), C-C (002) (referred as $\mathrm{P}_{2}$ ), C-C in-plane (100) (referred as $\mathrm{P}_{3}$ ), and C-C (110) peaks ${ }^{23}$. Compared to the highly fluorinated $\mathrm{CF}_{\mathrm{x}}(\mathrm{x}=1)$, the $\mathrm{d}$ value of 002 decreases to $6.5 \AA$ from $7.1 \AA$. It appears that there are no obvious changes for the the position and shape of the diffraction peaks after the modification. ${ }^{7}$ However, at a close inspection, the "blister" around $26.4^{\circ}$ emerges indicating the formation of carbon phase. A quantitative fitting of the peaks reveals that the intensity ratios of P2/P1 and P3/P1 increase from 0.41 to 0.74 and from 1.23 to 1.47 , respectively, after 
modification, indicating an increase in the carbon structure.

To understand how the local structure changes after modification, we carried out structural analysis using HRTEM and STEM. Figure 3 presents the STEM-HAADF and HRTEM images taken from F-MCMB (Figs 3a, 3b), and MF-MCMB particles (Figes 3c, 3d), respectively. The STEM-HAADF images show the conglomerations of small balls with the size about 200-300 $\mathrm{nm}$ for both samples, indicating that the morphology of the F-MCMB shows no significant change after modification. From the HRTEM images, the F-MCMB exhibits an irregular atomic arrangement inside the particle, which is commonly seen in fluorinated $\mathrm{CF}_{\mathrm{x}}$. Interestingly, there is a thin surface layer with 1 3 discontinuous lattice fringes (Fig. 3b), which is different from the highly fluorinated uniform $\mathrm{CF}_{\mathrm{x}}{ }^{21}$. The MF-MCMB has basically the same amorphous structure as the pristine inside the particle. However, the MF-MCMB has a thicker surface layer in which the fringes (more than 10) are more continuous and parallel to the surface (Fig. 3d). The spacing of the fringes varies from 0.5 to $0.55 \mathrm{~nm}$, which can be assigned to the self-assembly F-graphene layers during de-fluorination process.

To further confirm the structural changes on the surface of the MF-MCMB, EELS spectrum image analysis is carried out in the double aberration-corrected JEM-200CF. Figure 4 compares the relative compositions of $\mathrm{C}$ and $\mathrm{F}$ as a function of position cross the particle for F-MCMB and MF-MCMB calculated from the EELS spectrum image. The F concentration decreases linearly from the surface toward the core of the particle, then becomes constant in the core for the pristine particle (F-MCMB, Fig. 4a), which could be attributed to the surface tension release and F or 
HF diffusion during the fluorination ${ }^{22}$. In comparison, the F reduction in the modified particle (MF-MCMB, Fig. 4b) is more pronounced on the surface area, and basically follows the exponential reduction, as shown by the exponential fitting curves in Fig. 4b. The F reduction may even extend to the core of the particle. These results confirm the surface de-fluorination and the rearrangement of the F-graphene layers of the MF-MCMB particles, echoing the overall decrease of $\mathrm{CF}_{\mathrm{x}}$ structure (or the increase of carbon phase) revealed by XRD. Raman spectra of different $\mathrm{CF}_{\mathrm{x}}$ are depicted in Fig.5 and a pair of peaks is observed around $1340 \mathrm{~cm}^{-1}$ (D-band) and $1580 \mathrm{~cm}^{-1}$ (G-band). The intensity ratio of the $\mathrm{D}$ and $\mathrm{G}$ bands $\left(\mathrm{I}_{\mathrm{D}} / \mathrm{I}_{\mathrm{G}}\right)$ is known to depend on the number of defects within the $\mathrm{CF}_{\mathrm{x}}$ (the disorder-induced band). The $\mathrm{I}_{\mathrm{D}} / \mathrm{I}_{\mathrm{G}}$ ratio of F-MCMB is 1.1, thus confirming the presence of $\mathrm{C}-\mathrm{F} \mathrm{sp}{ }^{3}$ hybridized carbon atoms. On the other hand, the defect ratio for the MF-MCMB $\left(\mathrm{I}_{\mathrm{D}} / \mathrm{I}_{\mathrm{G}}=1.4\right)$ is higher, indicating the increase in defect concentration. The superior electrochemical performance of modified $\mathrm{CF}_{\mathrm{x}}$ can be attributed to the advantageous features offered by its unique microstructure.

The change of the surface structure can be further analyzed by surface-sensitive XPS. From the F1s XPS spectrum in Fig. 6a, a characteristic peak is found at 688.7 $\mathrm{eV}$ in F-MCMB (compared to the $689.8 \mathrm{eV}$ of the highly fluorinated $\mathrm{CF}_{\mathrm{x}}{ }^{21}$ ), which may be due to the carbon lattice of the starting material MCMB exhibiting a curvature structure. In comparison, a small shift of about $0.5 \mathrm{eV}$ is evident in Fig. 6b, revealing a change in the chemical environment for the F atoms after de-fluorination. The F1s peak in semi-ionic and ionic C-F bonds is located at $688.2 \mathrm{eV}$ and $685.9 \mathrm{eV}$ respectively ${ }^{14}$, from which we speculate that after modification, the C-F bonds are transformed into weaker covalent ones. (See detailed XPS peak fittings and assignments in Table S1). As shown in Figs. 6c and 6d, the C1s peaks of F-MCMB 
and MF-MCMB, C-containing ( $\mathrm{C}<\mathrm{sp}^{2}$, and $\mathrm{C}-\mathrm{sp}^{3}$ hybridization) and F-containing moieties $\left(\mathrm{sp}^{3}\right.$ hybridization, associated with the $-\mathrm{CF},-\mathrm{CF}_{2}$ and $-\mathrm{CF}_{3}$ groups) are exhibited. The normalized peak area ratio of F-containing and C-containing moieties for F-MCMB is estimated at 4.90 while a dramatic decrease to 1.20 for the MF-MCMB. Moreover, the difference between the F-containing and C-containing peaks for F-MCMB and MF-MCMB reduced from $5.1 \mathrm{eV}$ to $4.6 \mathrm{eV}$, which may be due to the formation of lower F content species, such as $\mathrm{C}-\mathrm{C}(\mathrm{CF})_{3}(288.2 \mathrm{eV})$ and $\mathrm{FC}(\mathrm{C})_{3}(289.2 \mathrm{eV})$ afterde-fluorination ${ }^{14}$, corresponding to graphite-like polytypes found by HRTEM, as shown in Fig. 6d. In fact, for the highly fluorinated $\mathrm{CF}_{\mathrm{x}}$, high $\mathrm{F}$ content species such as $\mathrm{FC}\left(\mathrm{CF}_{3}\right)_{2}$ (located at $291.0 \mathrm{eV}$ ) and $\mathrm{F}_{2} \mathrm{C}\left(\mathrm{CF}_{2}\right)_{2}(291.8 \mathrm{eV}$ ) groups are likely to be generated on the edge of sheets and at the defects in the precursor surface ${ }^{5,10}$. On the contrary, the bonding energy range for those high $\mathrm{F}$ content groups can hardly be found in MF-MCMB (Fig. 6d), which is also indicated in the FTIR results (Fig. 7). In addition, compared to the F-MCMB, the peak area ratio of C-containing to F-containing moieties for MF-MCMB is greatly enhanced (from 0.86 to 1.52). This increase could be attributed to the de-fluorination and rearrangement of the carbon atoms to form $\mathrm{C}-\mathrm{C}<$ bonds during the hydrothermal process.

From the FTIR spectra (Fig. 7), the F-MCMB exhibits an intense band centered at around $1218 \mathrm{~cm}^{-1}$, which is the characteristic band of the covalent C-F bond ${ }^{6}$. After modification, the MF-MCMB shifts to lower frequency of $1210 \mathrm{~cm}^{-1}$. The bands at 1342 and $1072 \mathrm{~cm}^{-1}$ (no so obvious), have been assigned to the asymmetric and symmetric stretching vibration of $>\mathrm{CF}_{2}$ groups at the edge of the $\mathrm{C}-\mathrm{C}$ layers, respectively. From the normalized spectra, the clear $1342 \mathrm{~cm}^{-1}$ band appears in the 
F-MCMB, suggesting the materials contain $>\mathrm{CF}_{2}$ groups. However, the MF-MCMB presents a very small peak at $1342 \mathrm{~cm}^{-1}$, indicating the $>\mathrm{CF}_{2}$ groups has been greatly removed after modification.

Coin cells 2016 were used to evaluate the electrochemical performance of the materials (Figs 8a, 8b). The F-MCMB composite cathode delivers a discharge capacity of $773 \mathrm{mAhg}^{-1}$ (theoretical value $814 \mathrm{mAh} \mathrm{g}^{-1}, \mathrm{CF}_{0.86}$ ) at $0.025 \mathrm{C}$, showing a slope plateau with average voltage of 2.6V. A voltage delay is totally cleared up. The C-F bond existing in the planar graphite-like $\mathrm{CF}_{\mathrm{x}}{ }^{21}$ is linear and simple, and exhibits a flat discharge voltage. Compared to the planar typed, the slope typed discharge curve may be due to the various curvature C-F bonds existing in F-MCMB, presenting an average effect. The higher the curvature of the C-F bond, the higher the potential presents because the covalence is weakened ${ }^{12,24}$.

The F-MCMB does not show any discharge curves voltage delay until 0.5C, revealing the voltage delay is rate dependent. Compared to the highly fluorinated $\mathrm{CF}_{\mathrm{x}}$, the electrochemical performances have been improved, which can be attributed to the open structure and less fluorinated phase with higher electron conductivity. Even that, the F-MCMB still can only deliver $500 \mathrm{mAh} \mathrm{g}^{-1}$ at 5C.The MF-MCMB cathode ( $\mathrm{x}=$ 0.80 estimated according to the F content of 58.7 wt\%) exerts a capacity of $756 \mathrm{mAh}$ $\mathrm{g}^{-1}$ at $0.025 \mathrm{C}$, with a slight higher average voltage of $2.63 \mathrm{~V}$. More interestingly, the voltage delay does not appear even at 5C, confirming the good electronic and ionic conductivities of the active particles at the initial stage of discharge ${ }^{9-15}$. Whereas $\mathrm{CF}_{\mathrm{x}}$ cathodes are known to suffer from sluggish kinetics, with the MF-MCMB electrodes demonstrated outstanding high rate capability. Even at the ultrafast rate of $40 \mathrm{C}$ (24 A 
$\mathrm{g}^{-1}$ ), a significant capacity of $343 \mathrm{mAh} \mathrm{g}^{-1}$ and a maximum power density of $54600 \mathrm{~W}$ $\mathrm{kg}^{-1}$ (based on the active material) can still be obtained. Clearly, lithium ions can still reach the inside of the active materials even at high rates. Compared to our report of modified Daikin CF, the faradic yield is lower, which may be due to the smaller d-spacing of 002 (6.5 $\AA$ vs. $7.1 \AA$ ). At high rates, the smaller d-spacing means the more difficulties for lithium ions to reach the inside of the material.

\section{Discussion}

It is well known that the good electronic and ionic conduction is expected to contribute to high capacity and high rate capability. Compared to the bulk shape of $\mathrm{CF}_{\mathrm{x}}$, the high open framework pinecone shaped hierarchical nanostructure provides facile electrolyte permeation and ion diffusion. Unfortunately, the inactive groups $-\mathrm{CF}_{2}$ and $-\mathrm{CF}_{3}$, are likely to be generated on the rich surface, causing surface electronic insulation and ionic traffic blocking. Additionally, the ball with an insulated surface is unlikely to form an effective electron conducting network with conductive additive. So, the pristine F-MCMB can only exert $500 \mathrm{mAh} \mathrm{g}^{-1}$ at $5 \mathrm{C}$. In contrast, after modification, the surface inactive groups are eliminated, and rearrangements occur to form a more electronic conductive surface (see HRTEM results in Figs. 3, 4 and XPS, FTIR results in Fig.7). Thus, an effective conducting network can be formed. The increase of electronic conductivity of MF-MCMB is supported by first principles all-electron calculations in a former report ${ }^{21}$. More importantly, since surface inactive groups have been removed to a significant extent, ion transport is improved ${ }^{25,26}$. Once the limitations are removed, the advantages of the open frame hierarchical structure can be realized where ultrafast rate performance with high capacity can be achieved. 
To better understand our findings, an analysis of electrochemical impedance spectrum (EIS) at open circuit voltage (OCV) was performed. Both of the Nyquist plots contain a depressed semicircle in high frequencies and a straight line in low frequencies (Fig. 9a). Interpretation of the impedance spectra was based on the equivalent circuit in Fig. 9b. The bulk Ohmic resistance $\left(R_{b}\right)$ contributed to the combination of current collector, electrolyte, separator and electrode, presents no obvious difference for the both cells. On the interface between the liquid electrolyte and the particle shell of $\mathrm{CF}_{\mathrm{x}}$, the charge-transfer through an existing electric double layer can be characterized by $\mathrm{Q}_{\mathrm{ct}}$ and $\mathrm{R}_{\mathrm{ct}}$ at high frequency. $\mathrm{R}_{\mathrm{ct}}$ is the synergetic effects of the constant resistance among conductive particles, particle shell resistance and charge-transfer resistance, corresponding to the depressed semicircle in the impedance plot. And $\mathrm{Q}_{\text {int }}$ is the constant phase element applied due to the lack of lithium ion diffusion in the active materials. Clearly, the cell reaction resistance $\left(\mathrm{R}_{\mathrm{ct}}\right.$, the semicircles) of the MF-MCMB are only about one third that of the F-MCMB, revealing the low resistance and improved conductivity. The onset between the semicircle and the sloped line are indicative of reaction kinetics with higher frequencies representing faster reaction kinetics ${ }^{10,}{ }^{17,}{ }^{21}$. Therefore, the EIS measurements corroborated the effective increase of electron and ion transfer by the modified MF-MCMB electrode.

Regarding voltage delay, many reports attribute it to the insulating behavior of the initial $\mathrm{CF}_{\mathrm{x}}$, which is the issue of electron conductivity. The obvious rate dependent phenomenon of the F-MCMB and MF-MCMB suggests that the voltage delay is not only related to the electron conductivity but also to ion conductivity. It can be supposed that when the "ion supply" is deficient, the voltage delay occurs. After 
modification, the surface conductivity of the particle has been greatly improved, and the ion supply can be more efficient since the ion-blocking barrier has been removed, so the voltage delay can be minimized to a certain extent. However, when the rate is high enough (> $10 \mathrm{C}$ ), "ion depletion” will take place at the first of the discharge, leading to voltage delay. Further efforts to minimize the voltage delay through improving the interface for ion diffusion, such as the design of a more open structure and conductive particle, could be adopted.

\section{Conclusions}

In conclusion, a surface de-fluorinated pinecone shaped hierarchical structure fluorinated MCMB has been developed as a high power high energy density $\mathrm{Li} / \mathrm{CF}_{\mathrm{x}}$ battery cathode material. The modified MF-MCMB, manifesting the advantage of open-framework particle, possesses good electronic conductivity deprived of transport barriers (such as $-\mathrm{CF}_{2},-\mathrm{CF}_{3}$ groups) for lithium ions. Thus, high capacity performance and excellent rate capability without compromising capacity can be obtained. A capacity of $343 \mathrm{mAh} \mathrm{g}^{-1}$ and a maximum power density of $54600 \mathrm{~W} \mathrm{~kg}^{-1}$ are realized at ultrafast rate of $40 \mathrm{C}\left(28 \mathrm{Ag}^{-1}\right)$. The discharge curves in the F-MCMB and MF-MCMB electrodes indicate the voltage delay is rate dependent, suggesting that ion transport is another important factor contributed to the phenomenon. It is interesting that the MF-MCMB does not present any voltage delay until 5C discharge. The minimized voltage delay in the MF-MCMB electrode may originate from the highly conducting surface, barrier free ion diffusion and the open framework hierarchical structure. Our findings demonstrate a new route and model material to achieve high power density, minimized voltage delay for a high performing $\mathrm{Li} / \mathrm{CF}_{\mathrm{x}}$ battery. More importantly, this report provides a new way to design and prepare high 
performance $\mathrm{CF}_{\mathrm{x}}$ cathode material for applications ranging from space exploration to life-saving medical devices.

\section{References}

1. N. Watanabe and M. Fukuda, US Pat. 3,536,532 (1970) and 3,700,502 (1972).

2. N. Watanabe, T. Nakajima and H. Touhara, Graphite Fluorides, Elsevier, Amsterdam, (1988).

3. A. Hamwi, K. Guerin and M. Dubois, Fluorinated Materials for Energy Conversion, Elsevier, Oxford, UK, (2005).

4. E. Rangasamy, J. Li, G. Sahu, N. Dudney, C. Liang, J. Am. Chem. Soc. 136 (19), 6874, (2014).

5. Y. Ahmad, M. Dubois, K. Guérin, A. Hamwi, and W. Zhang, Carbon, 94, 1061, (2015).

6. D. C. Bock, A. C. Marschilok, K. J. Takeuchi and E. S. Takeuchi, Electrochim. Acta, 84, 155, (2012).

7. S. Davis, E. S. Takeuchi, W. Tiedemann and J. Newman, J. Electrochem. Soc., 154, A477, (2007).

8. S. Davis, E. S. Takeuchi, W. Tiedemann and J. Newman, J. Electrochem. Soc.,155, A24 (2008).

9. R. Yazami, A. Hamwi, K. Guerin, Y. Ozawa, M. Dubois, J. Giraudet, F. Masin 
Electrochem. Commun. 9, 1850, (2007).

10. P. Meduri, H. Chen, X. Chen, J. Xiao, M. Gross, T. Carlson, J.-G. Zhang, Z. D. Deng, Electrochem. Commun. 13, 1344, (2011).

11. H. Groult, C. M. Julien, A. Bahloul, S. Leclerc, E. Briot, A. Mauger. Electrochem. Commun. 13, 1074 (2011).

12. M. Dubois, K. Guérin, W. Zhang, Y. Ahmad, A. Hamwi, Z. Fawal, H. Kharbache, F. Masin, Electrochimica Acta 59, 485, (2012).

13. P. Lam, R. Yazami, J. Power Sources, 153, 354 (2006).

14. P. F. Fulvio, S. S. Brown, J. Adcock, R. T. Mayes, B. Guo, X.-G. Sun, S. M.

Mahurin, G. M. Veith, S. Dai. Chem. Mater. 23, 4420 (2011).

15. C. Sun, Y. Feng, Y. Li, C. Qin, Q. Zhang, W. Feng, Nanoscale, 6, 2634, (2014).

16. Q. Zhang, S. D’Astorg, P. Xiao, X. Zhang, L. Lu, J. Power Sources 195, 2914 (2010).

17. C. Pang, F. Ding, W. Sun, J. Liu, M. Hao, Y. Wang, X. Liu, and Q.

Xu, Electrochimica Acta, 174, 230, (2015).

18. W. Yang, Y. Dai, S. Cai, Y. Zheng, W. Wen, K. Wang, Y. Feng, J. Xie, J. Power Sources 255, 37 (2014).

19. Q. Zhang, K. J. Takeuchi, E. S. Takeuchi, A. C. Marschilok, Phys. Chem. Chem. Phys.,17, 22504 (2015).

20. S. S. Zhang, D. Foster, J. Read, J. Power Sources 188, 601 (2009).

21. Y. Dai, S. Cai, L. Wu, W. Yang, J. Xie, W. Wen, J.C. Zheng, and Y. Zhu, J. Mater. Chem. A, 2, 20896 (2014). 
22. J. Zhang, J. Shi, G. Wu, X. Guo, Q. Guo, and L. Liu, Carbon, 49(5), 1628, (2011).

23. K. Guérin, J. P. Pinheiro, M. Dubois, Z. Fawal, F. Masin, R. Yazami, and A.

Hamwi, Chem. Mater., 16(9), 1786 (2004).

24. W. Zhang, M. Dubois, K. Guérin, P. Bonnet, H. Kharbache, F. Masin, A. P. Masin,

A. Kharitonov, and A. Hamwi, Phys. Chem. Chem. Phys., 12(6), 1388, (2010).

25. T. Brezesinski, J. Wang, S. H. Tolbert , B. Dunn, Nature materials 9, 146 (2010).

26. A. Magasinski, P. Dixon, B. Hertzberg, A. Kvit, J. Ayala G. Yushin, Nature materials 9, 353 (2010).

22. J. Zhang, J. Shi, G. Wu, X. Guo, Q. Guo, and L. Liu, Carbon, 49(5), 1628, (2011).

23. K. Guérin, J. P. Pinheiro, M. Dubois, Z. Fawal, F. Masin, R. Yazami, and A. Hamwi, Chem. Mater., 16(9), 1786 (2004).

24. W. Zhang, M. Dubois, K. Guérin, P. Bonnet, H. Kharbache, F. Masin, A.P. Masin, A. Kharitonov, and A. Hamwi, Phys. Chem. Chem. Phys., 12(6), 1388, (2010).

25. T. Brezesinski, J. Wang, S. H. Tolbert, B. Dunn, Nature materials 9, 146 (2010).

26. A. Magasinski, P. Dixon, B. Hertzberg, A. Kvit, J. Ayala G. Yushin, Nature materials 9, 353 (2010).

\section{Acknowledgements}

Financial support from the National Natural Science Foundation of China (No. 21103109, No. 21176152 No. 21373137, No. 11335006), the National High-tech R\&D Program of China (863 Program, No. 2014AA052202) and Program (No. ZZSD15115) are greatly appreciated. The work at Brookhaven National Laboratory is supported by the U.S. Department of Energy, Office of Basic Energy Sciences, under 
Contract No. DE-SC0012704. EST acknowledges the Center for Mesoscale Transport Properties, an Energy Frontier Research Center supported by the U.S. Department of Energy, Office of Science, Basic Energy Sciences, under award \#DE-SC0012673 for financial support.

\section{Figure caption}

Fig.1. The SEM images of the F-MCMB (a) and MF-MCMB powders (b).Conductivity difference in the two materials is visible from the SEM images, blur for the pristine but much clearer for the modified one.

Fig. 2. XRD patterns of F-MCMB and MF-MCMB. No distinct changes can be found either in diffraction peaks or their shapes after the hydrothermal treatment, which means that the modification does not affect the core of the particles.

Fig. 3. (a, c) STEM-HAADF and (b, d) HRTEM images taken from F-MCMB (a, b) and MF-MCMB (c, d) samples. Although there appears a thin layer with 1 3 fringes on the surface of pristine particles, it is not uniform, nor continuous. In the modified particles, however, there is a thick, continuous surface layer with about 10 fringes on the surface. 
Fig. 4. Relative composition of C (blue crosses and black circles) and F (green crosses and red circles) as a function of the position cross a particle for (a) pristine F-MCMB (blue and green crosses) and (b) modified MF-MCMB (red and black circles) derived from the EELS spectrum images. The orange line is the simultaneously acquired STEM-HAADF intensity signals. The corresponding survey STEM-HAADF images are embedded in the bottom of the profiles. The green arrow marks the scan line for EELS spectrum image. The red and black lines superimposed onto the data points on the left side of the plot in (a) are linear fits for $\mathrm{C}$ and $\mathrm{F}$ compositions of the pristine particle, respectively. The green and blue curves on the left side of the plot in (b) are the fits for the $\mathrm{C}$ and $\mathrm{F}$ compositions of the modified particle using exponential function.

Fig. 5. Raman spectra of (a) F-MCMB and (b) MF-MCMB. The peaks of D-band and G-band are also indicated. Higher $\mathrm{I}_{\mathrm{D}} / \mathrm{I}_{\mathrm{G}}$ ratio (1.4) for modified $\mathrm{CF}_{\mathrm{x}}$ compared to that of pristine $\mathrm{CF}_{\mathrm{x}}(1.1)$ indicates higher defect concentration after de-fluorination.

Fig. 6. X-ray photoelectron spectra of F1s for (a) F-MCMB and (b) MF-MCMB; and C1s for (c) F-MCMB and (d) MF-MCMB. (b) shows a shift to a lower binding energy of about $0.5 \mathrm{eV}$ in comparison with (a).

Fig. 7. FTIR spectra of the F-MCMB and MF-MCMB. After modification, the MF-MCMB presents a very small peak at $1342 \mathrm{~cm}^{-1}$, indicating the $>\mathrm{CF}_{2}$ groups has been greatly removed. 
Fig. 8. Discharge profiles of (a) F-MCMB and (b) MF-MCMB. The voltage delay phenomenon is eliminated even at the rate of 5C.

Fig. 9. (a) Electrochemical impedance spectra for F-MCMB, MF-MCMB electrodes at OCV, and (b) the equivalent circuit.

Tab. 1. XPS assignments and concentrations for the F-MCMB and modified MF-MCMB investigated. 
Fig. 1.

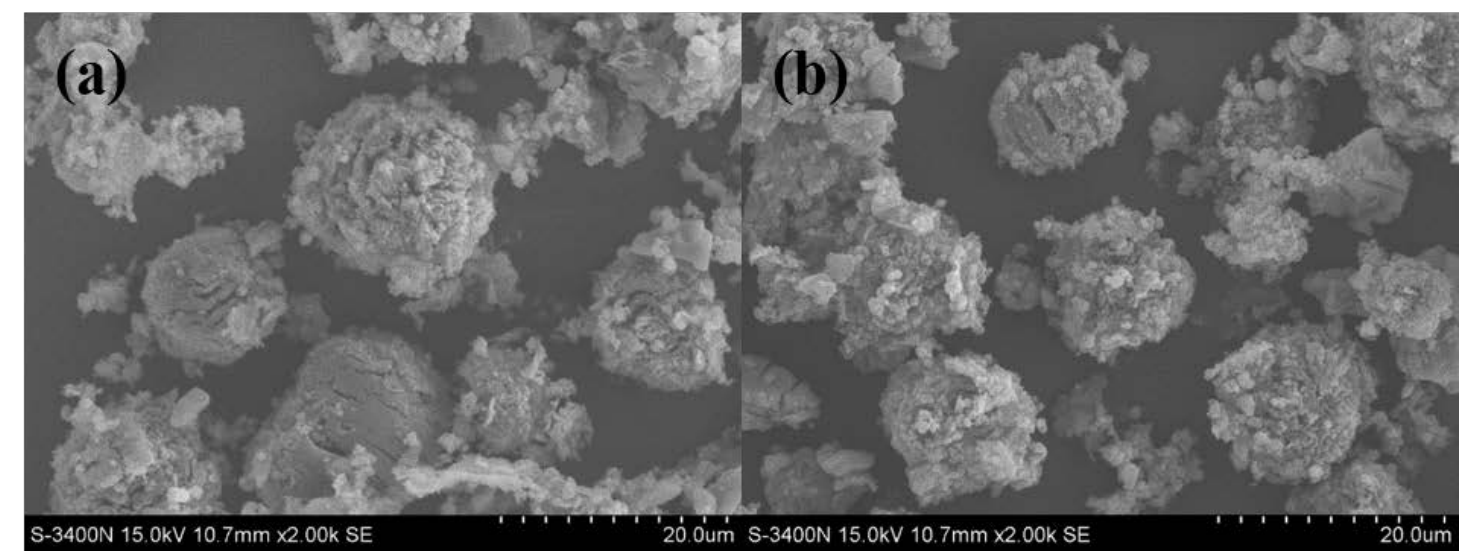


Fig.2.

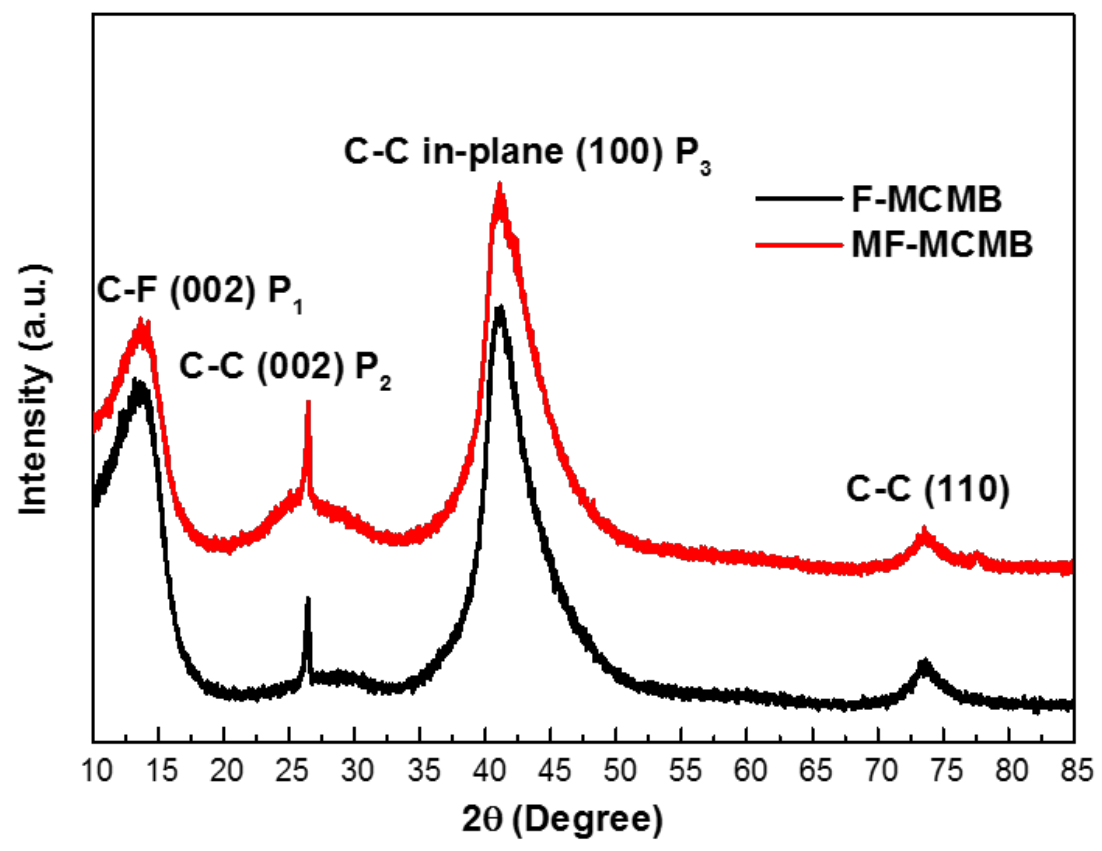


Fig.3.

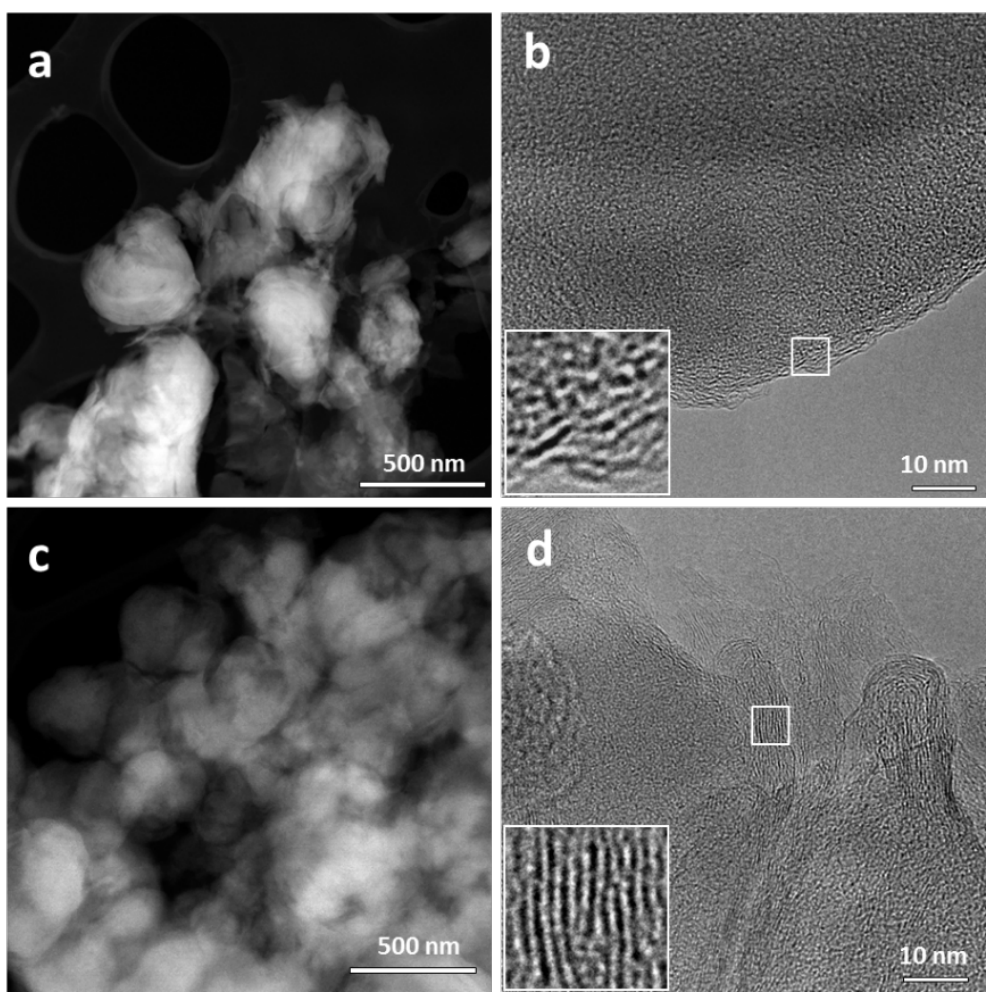


Fig.4.
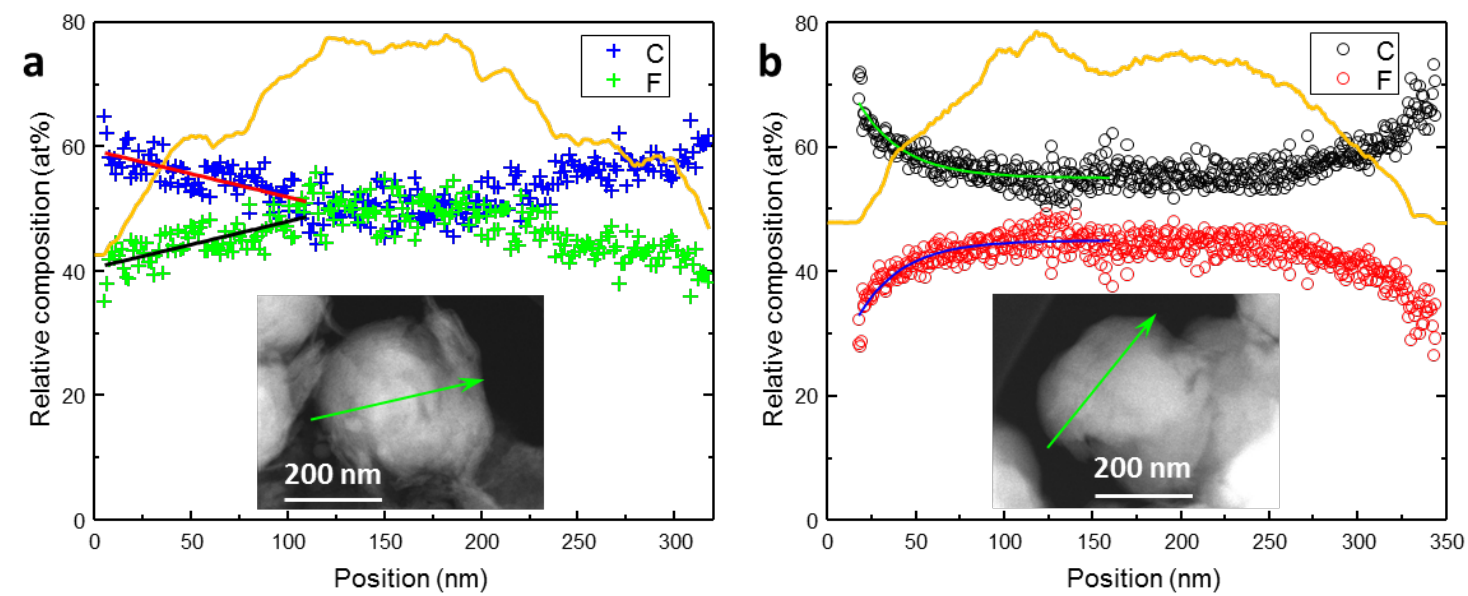
Fig. 5.

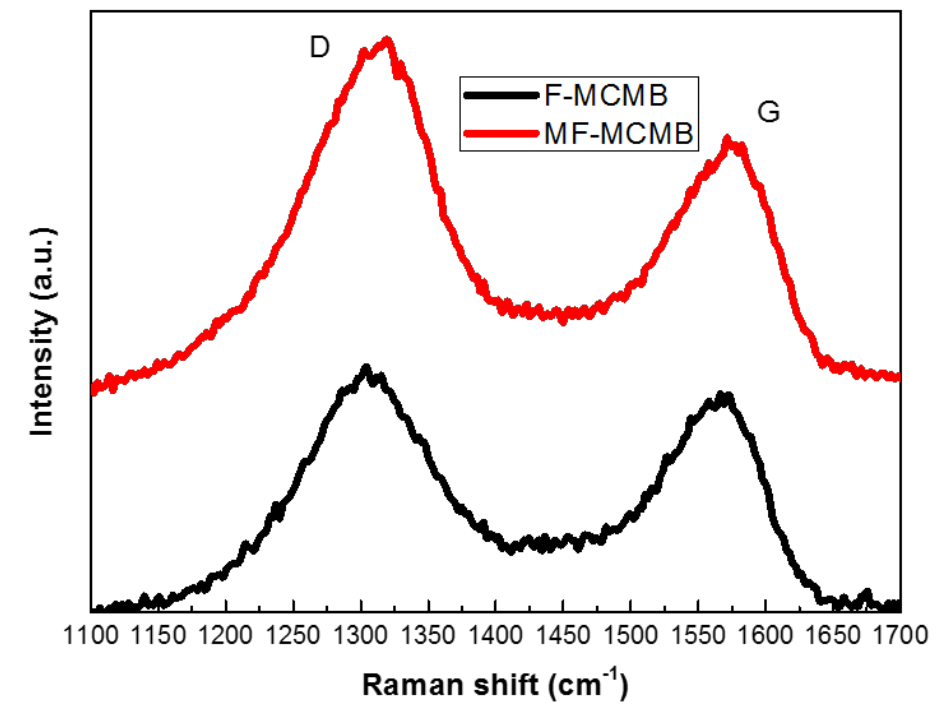


Fig. 6.
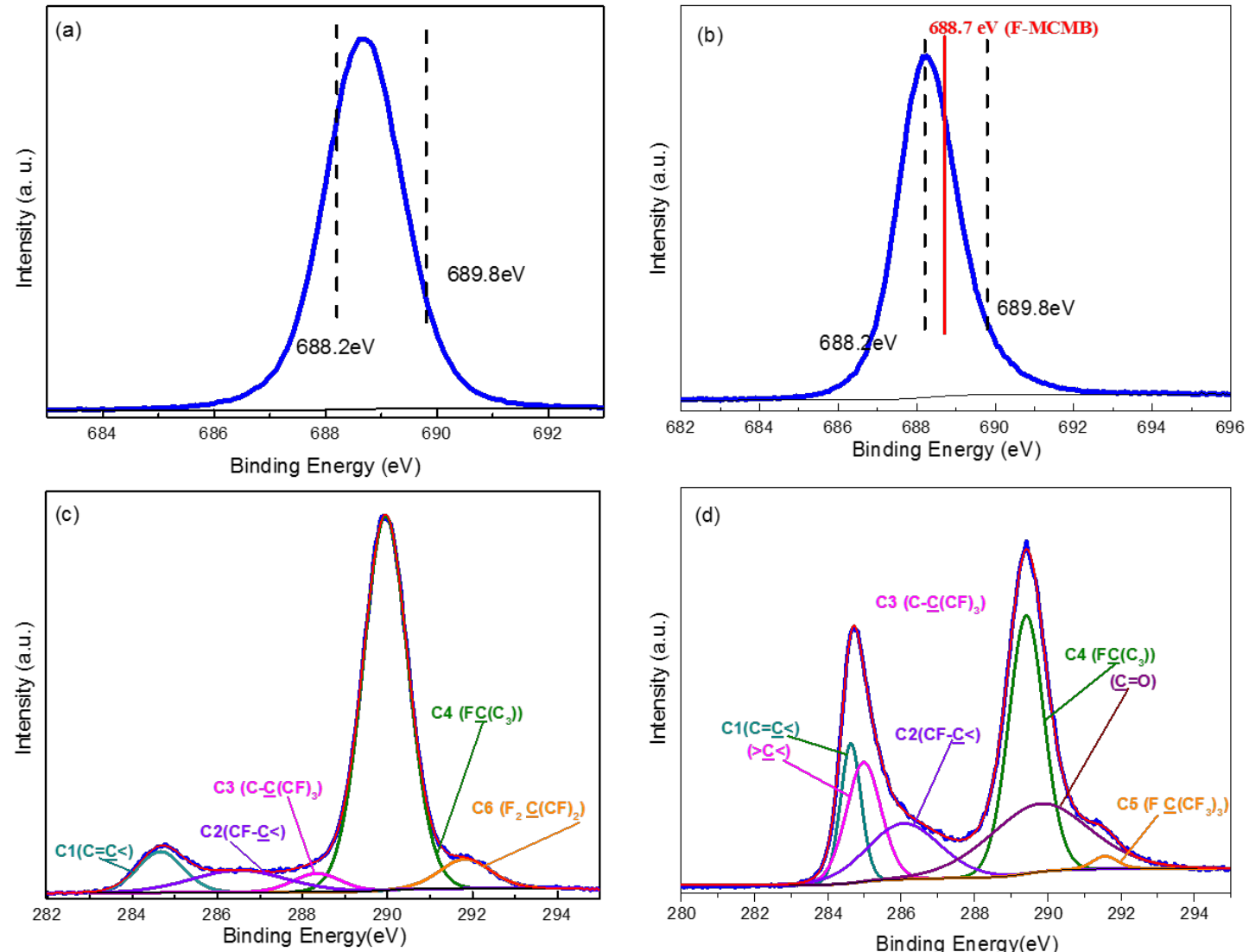
Fig. 7.

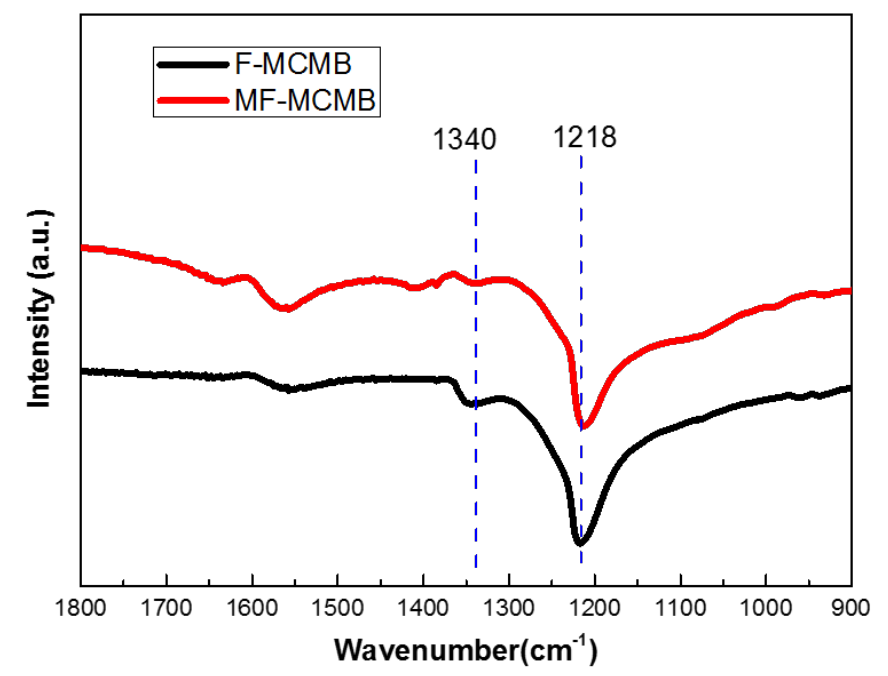


Fig.8.
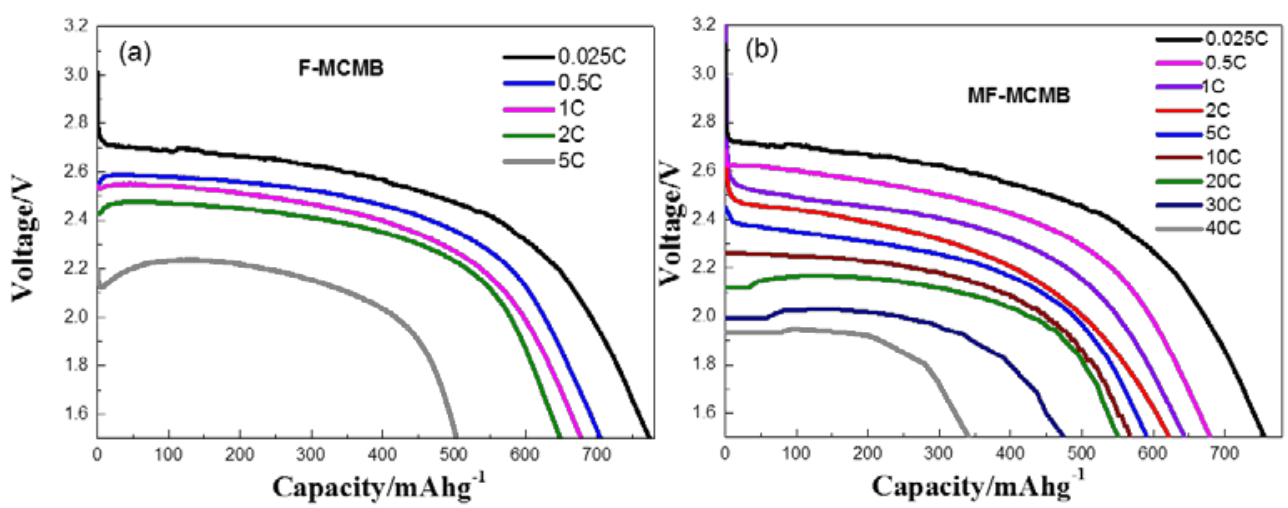
Fig.9.

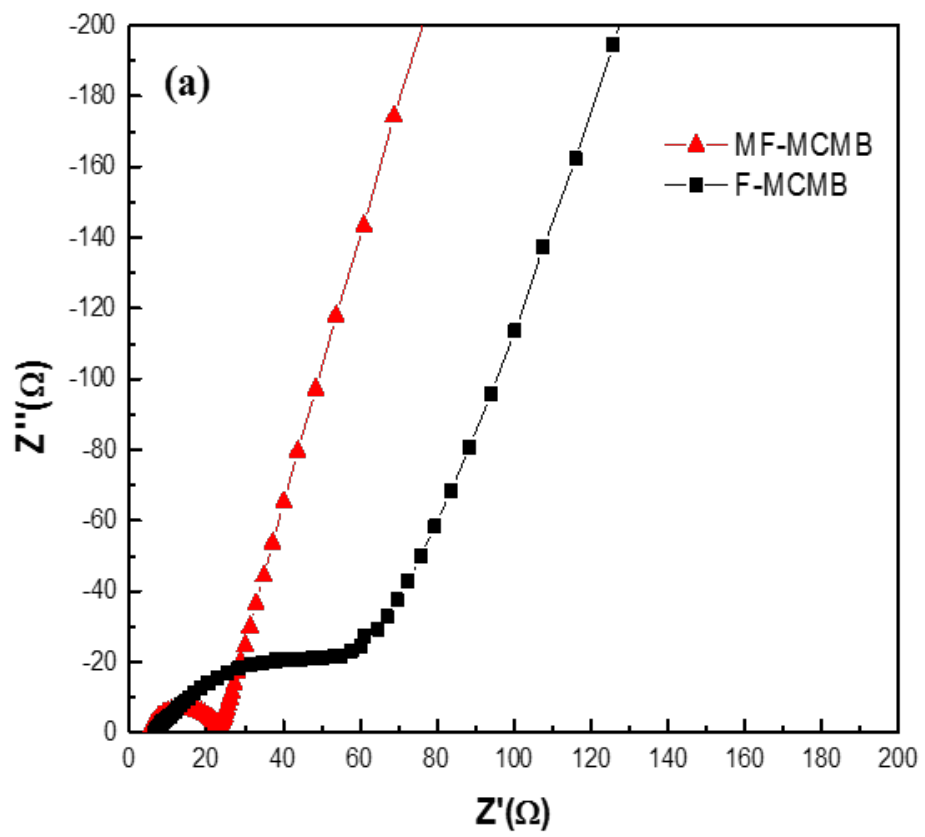

(b)

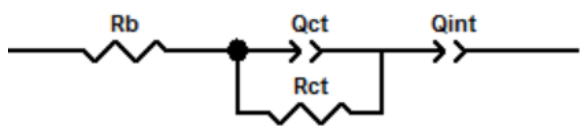

Equivalent circuit 
Tab. 1

\begin{tabular}{|c|c|c|c|c|c|c|}
\hline Peak & Structures & $\begin{array}{c}\text { Peaks } \\
\text { Assignment } \\
\text { /eV }\end{array}$ & $\begin{array}{c}\text { F-MCMB } \\
\text { Peaks } \\
\text { Assignment/eV }\end{array}$ & $\begin{array}{c}\text { F-MCMB } \\
\text { Normalized } \\
\text { peak area/ \% }\end{array}$ & $\begin{array}{c}\text { MF-MCMB } \\
\text { Peaks } \\
\text { Assignment/eV }\end{array}$ & $\begin{array}{c}\text { MF-MCMB } \\
\text { Normalized } \\
\text { peak area/ \% }\end{array}$ \\
\hline $\mathrm{C} 1$ & $\begin{array}{c}\mathrm{C}=\underline{\mathrm{C}}< \\
>\underline{\mathrm{C}}<\end{array}$ & 284.8 & 284.7 & 8.01 & $\begin{array}{l}284.6 \\
285.0 \\
\end{array}$ & $\begin{array}{l}10.51 \\
15.20 \\
\end{array}$ \\
\hline $\mathrm{C} 2$ & $\begin{array}{c}\mathrm{CF}-\underline{\mathrm{C}}< \\
\mathrm{C}-\mathrm{O}\end{array}$ & 286.2 & 286.5 & 8.97 & 286.1 & 14.82 \\
\hline $\mathrm{C} 3$ & $\mathrm{C}-\underline{\mathrm{C}}(\mathrm{CF})_{3}$ & 288.1 & 288.3 & 3.84 & - & - \\
\hline $\mathrm{C} 4$ & $\begin{array}{c}\mathrm{FC}\left(\mathrm{C}_{3}\right) \\
\mathrm{C}=\mathrm{O}\end{array}$ & 289.1 & 289.9 & 72.7 & $\begin{array}{l}289.4 \\
289.8 \\
\end{array}$ & $\begin{array}{l}33.43 \\
24.88 \\
\end{array}$ \\
\hline $\mathrm{C} 5$ & $\mathrm{~F} \underline{\underline{C}}\left(\mathrm{CF}_{3}\right)_{3}$ & 291.0 & - & - & 291.6 & 1.17 \\
\hline C6 & $\begin{array}{l}\mathrm{F}_{2} \mathrm{C}(\mathrm{CF})_{2}, \\
\mathrm{~F}_{2} \underline{\mathrm{C}}\left(\mathrm{CF}_{2}\right)_{2}\end{array}$ & 292.5 & 291.8 & 6.48 & - & - \\
\hline F1 & $\left(\mathrm{C}_{\mathrm{X}} \mathrm{F}\right)_{\mathrm{n}}$ & Semi-ionic & 688.2 & - & 688.2 & - \\
\hline $\mathrm{F} 2$ & $(\mathrm{CF})_{\mathrm{n}}$ & Covalent & 689.5 & - & 689.8 & - \\
\hline
\end{tabular}

